\title{
Влияние отжига во фреоне на кристаллическую структуру слоев теллурида кадмия и эффективность пленочных фотоэлектрических преобразователей на их основе
}

\author{
(C) Г.С. Хрипунов, А.В. Мериуц, Т.Н. Шелест, М.Г. Хрипунов \\ Национальный технический университет „Харьковский политехнический институт“, \\ 61002 Харьков, Украина \\ E-mail: khrip@ukr.net
}

(Получена 22 марта 2018 г. Принята к печати 10 апреля 2018 г.)

Исследованы фотоэлектрические преобразователи на основе базовых слоев теллурида кадмия, полученных методом термического испарения и сублимацией в замкнутом объеме. Для активации базовых слоев использован отжиг в парах фреона. Проведены структурные и морфологические исследования для сравнения рекристаллизационных процессов, происходящих в процессе отжига в слоях теллурида кадмия, полученных разными методами. Исследованы выходные параметры и световые диодные характеристики фотоэлектрических преобразователей и проанализирована возможность применения отжига в парах фреона при создании промышленной технологии получения пленочных фотоэлектрических преобразователей на основе $\mathrm{CdS} / \mathrm{CdTe}$ с использованием термических методов формирования базовых слоев.

DOI: 10.21883/FTP.2019.01.46994.8871

\section{1. Введение}

В настоящее время обязательной технологической операцией при изготовлении высокоэффективных пленочных солнечных элементов (СЭ) на основе $\mathrm{CdS} / \mathrm{CdTe}$ является „хлоридная“ термообработка [1]. При твердотельной „хлоридной“ обработке слой $\mathrm{CdCl}_{2}$ на поверхности CdTe формируется лазерным или термическим испарением или химическим осаждением из раствора $\mathrm{CdCl}_{2}$ в метаноле. Затем, в независимости от способа формирования слоя $\mathrm{CdCl}_{2}$, проводится отжиг гетеросистемы $\mathrm{CdCl}_{2} / \mathrm{CdTe} / \mathrm{CdS}$ на воздухе в течение $10-30$ мин. Оптимальное время, температуру отжига и толщину $\mathrm{CdCl}_{2}$ определяют экспериментально, и они имеют широкий разброс. Затем проводится травление базового слоя для удаления продуктов химической реакции. Такая обработка приводит к увеличению эффективности СЭ в 3-6 раз [2]. Положительное влияние „хлоридной“ обработки связывают с ростом размеров зерен теллурида кадмия и сульфида кадмия, снижением удельного электросопротивления базового слоя за счет образования акцепторов $\mathrm{Cl}_{\mathrm{Te}}-\mathrm{V}_{\mathrm{Cd}}$, увеличением времени жизни неравновесных носителей заряда и сменой механизма зарядопереноса. Структурные изменения, происходящие в процессе „хлоридной“ обработки, обусловлены процессами перекристаллизации теллурида кадмия.

В последнее время ведутся интенсивные исследования по поиску других более технологичных, в условиях массового производства, методов „хлоридной“ обработки. Так, в [3] слои теллурида кадмия, полученные методом осаждения в замкнутом объеме, были отожжены в атмосфере аргона, содержащей фреон, при этом удалось получить приборные структуры с эффективностью более $14 \%$. Фреон является нетоксичным газом, и после отжига с применением фреона нет необходимости в травлении поверхности теллурида кадмия для удаления продуктов химической реакции. Это позволяет говорить, что обработка во фреоне является перспективной для применения в условиях массового производства.

Метод осаждения в замкнутом объеме позволяет получить слои теллурида кадмия для СЭ с рекордными значениями кпд, но при этом является достаточно дорогим в производстве. В то же время таким экономичным и хорошо адаптированным к промышленному производству методом, как термическое вакуумное испарение, получены высокоэффективные СЭ на основе $\mathrm{CdS} / \mathrm{CdTe}$. Однако при изготовлении таких приборных структур применялась традиционная „хлоридная“ обработка с нанесением слоя $\mathrm{CdCl}_{2}$ [4].

В данной работе мы исследуем возможность замены традиционной „хлоридной“ обработки на отжиг в парах фреона при создании экономичной промышленной технологии получения пленочных СЭ на основе $\mathrm{CdS} / \mathrm{CdTe}$, с использованием термических методов формирования базовых слоев. Для этого мы сопоставим структурные характеристики базовых слоев, полученных методом сублимации в замкнутом объеме и методом термического вакуумного испарения после отжига в парах фреона. Будет также проведен анализ выходных параметров и световых диодных характеристик солнечных элементов, полученных с использованием этих слоев.

\section{2. Методика эксперимента}

Для создания пленочных $\mathrm{C} Э \mathrm{FTO} / \mathrm{CdS} / \mathrm{CdTe} / \mathrm{Cu} / \mathrm{Au}$ на стеклянную подложку со слоем прозрачного проводящего окисла олова, легированного фтором (FTO), в едином технологическом цикле методом термического вакуумного испарения последовательно осаждались слои сульфида и теллурида кадмия. Температура подложки 
при осаждении пленок $\mathrm{CdS}$ составляла $150^{\circ} \mathrm{C}$, толщина слоев 0.4 мкм. При осаждении слоев CdTe толщиной 4 мкм температура подложки составляла $300^{\circ} \mathrm{C}$. К полученным приборным гетеросистемам применялись две технологии активации базового слоя: „хлоридная“ обработка и отжиг в парах фреона. При реализации „хлоридной“ обработки на поверхность слоя теллурида кадмия методом термического испарения без нагрева подложки наносились слои хлорида кадмия толщиной 0.6 мкм. Затем проводился отжиг на воздухе при температуре $430^{\circ} \mathrm{C}$ в течение 30 мин. Затем в растворе брома в метаноле проводилось травление базового слоя для удаления продуктов химической реакции. При проведении отжига в парах фреона приборные гетероструктуры размещались в кварцевых ампулах, в которых создавалась атмосфера аргона, содержащего $15 \% \mathrm{HCF}_{2} \mathrm{Cl}$ при давлении 100 мбар. Затем проводился отжиг при температуре $400-500^{\circ} \mathrm{C}$ в течение $20-40$ мин. Затем методом вакуумного термического осаждения формировались двухслойные контакты $\mathrm{Cu} / \mathrm{Au}$.

Солнечные элементы с базовым слоем теллурида кадмия, сформированным сублимацией в замкнутом объеме, были получены в группе физики тонких пленок физического факультета Университета Пармы (Италия), которую возглавляет проф. Никола Ромео с асп. Стефаном Бухелером. Для формирования фронтальных электродов СЭ на стеклянные подложки методом магнетронного распыления на постоянном токе в атмосфере аргона и кислорода были осаждены слои оксида индия и олова (ITO). После чего на эти слои были нанесены наноразмерные слои нелегированного оксида олова толщиной 0.1 мкм. Далее методом высокочастотного магнетронного распыления в атмосфере $\mathrm{CHF}_{3}$ осаждались слои сульфида кадмия толщиной 0.1 мкм. Базовый слой теллурида кадмия был сформирован методом сублимации в замкнутом объеме (CSS) при температуре подложки $520^{\circ} \mathrm{C}$ и температуре испарителя $600^{\circ} \mathrm{C}$. Затем был проведен отжиг во фреоне при температуре $400^{\circ} \mathrm{C}$ в течение 20-40 мин. Для этого в вакуумную камеру с атмосферой аргона при давлении 100 мбар добавляли фреон с парциальным давлением 15 мбар. После отжига во фреоне сразу формировался двуслойный тыльный контакт $\mathrm{Sb}_{2} \mathrm{Te}_{3} / \mathrm{Mo}$. Таким образом, были получены приборные структуры glass/ITO/ $\mathrm{SnO}_{2} / \mathrm{CdS} / \mathrm{CdTe} / \mathrm{Sb}_{2} \mathrm{Te}_{3} / \mathrm{Mo}$.

Для исследования структурных особенностей базовых слоев СЭ был использован метод рентгеновской дифрактометрии. Определение преимущественной ориентации пленок осуществлялось путем аналитической обработки дифракционных максимумов, полученных по максимальному текстурному коэффициенту $C_{i}$. Для сопоставления образцов по степени текстурированности рассчитывался параметр $G$ [5]. Прецизионное определение периода решетки базовых слоев теллурида кадмия проводилось с использованием экстраполяционной функции $\left(\cos ^{2} \theta / \sin \theta\right)+\left(\cos ^{2} \theta / \theta\right)$ [5]. Для исследования морфологии поверхности применялись методы сканирующей электронной микроскопии.
В условиях освещения АМ 1 при мощности светового потока $100 \mathrm{MBT} / \mathrm{cm}^{2}$ были измерены световые вольт-амперные характеристики (ВАХ) изготовленных приборных структур и экспериментально определены выходные параметры: плотность тока короткого замыкания $\left(J_{\mathrm{sc}}\right)$, напряжение холостого хода $\left(U_{\mathrm{oc}}\right)$, фактор заполнения (FF) нагрузочной световой ВАХ и в конечном итоге - коэффициент полезного действия (кпд) $(\eta)$. Согласно эквивалентной схеме СЭ, количественными характеристиками фотоэлектрических процессов являются световые диодные характеристики солнечного элемента: плотность фототока $\left(J_{\mathrm{ph}}\right)$, плотность диодного тока насыщения $\left(J_{0}\right)$, коэффициент идеальности диода $(A)$, последовательное сопротивление $\left(R_{S}\right)$ и шунтирующее сопротивление $\left(R_{\mathrm{sh}}\right)$, рассчитываемые на единицу площади СЭ.

Связь эффективности СЭ со световыми диодными характеристиками в неявном виде описывается теоретической световой ВАХ СЭ [6]:

$$
\begin{aligned}
J=-J_{\mathrm{ph}}+J_{0}\{\exp [e(U & \left.\left.\left.-J R_{S}\right) /\left(A k_{\mathrm{B}} T\right)\right]-1\right\} \\
& +\left(U-J R_{S}\right) / R_{\mathrm{sh}},
\end{aligned}
$$

где $J$ - плотность тока, протекающего через нагрузку, $e$ - заряд электрона, $k_{\mathrm{B}}-$ постоянная Больцмана, $T$ - температура солнечного элемента, $U$ - падение напряжения на нагрузке.

В соответствии с выражением (1) из экспериментальных ВАХ были рассчитаны световые диодные характеристики и кпд СЭ. При этом величина кпд, рассчитанная с помощью теоретической световой ВАХ и определенная экспериментально, совпадала с точностью $0.05 \%$. Анализируя выражение (1), можно показать, что с ростом $J_{\mathrm{ph}}, R_{\mathrm{sh}}$ и с уменьшением $J_{0}, A, R_{s}$ эффективность СЭ возрастает. Величина плотности фототока, которая количественно характеризует эффективность процессов генерации и диффузии неравновесных носителей заряда, определяется количеством фотонов, поступающих в базовый слой, квантовым выходом фотоэффекта и временем жизни неравновесных носителей заряда в базовом слое. Значения коэффициента идеальности и величина плотности диодного тока насыщения, которые количественно характеризуют эффективность процесса разделения неравновесных носителей заряда в пленочном поликристаллическом СЭ, контролируются временем жизни неравновесных носителей заряда, скоростью их рекомбинации в области пространственного заряда и энергетической структурой сепарирующего барьера. Шунтирующее сопротивление включено в эквивалентную схему СЭ, чтобы учесть влияние на эффективность фотоэлектрических процессов низкого электросопротивления локальных частей приборной структуры (например, границ зерен). Последовательное электросопротивление СЭ, величина которого определяет эффективность собирания неравновесных носителей заряда, зависит от электропроводности базового и сопрягающихся слоев СЭ, контактного сопротивления и скорости рекомбинации неравновесных носителей заряда на тыльных и фронтальных контактах. 

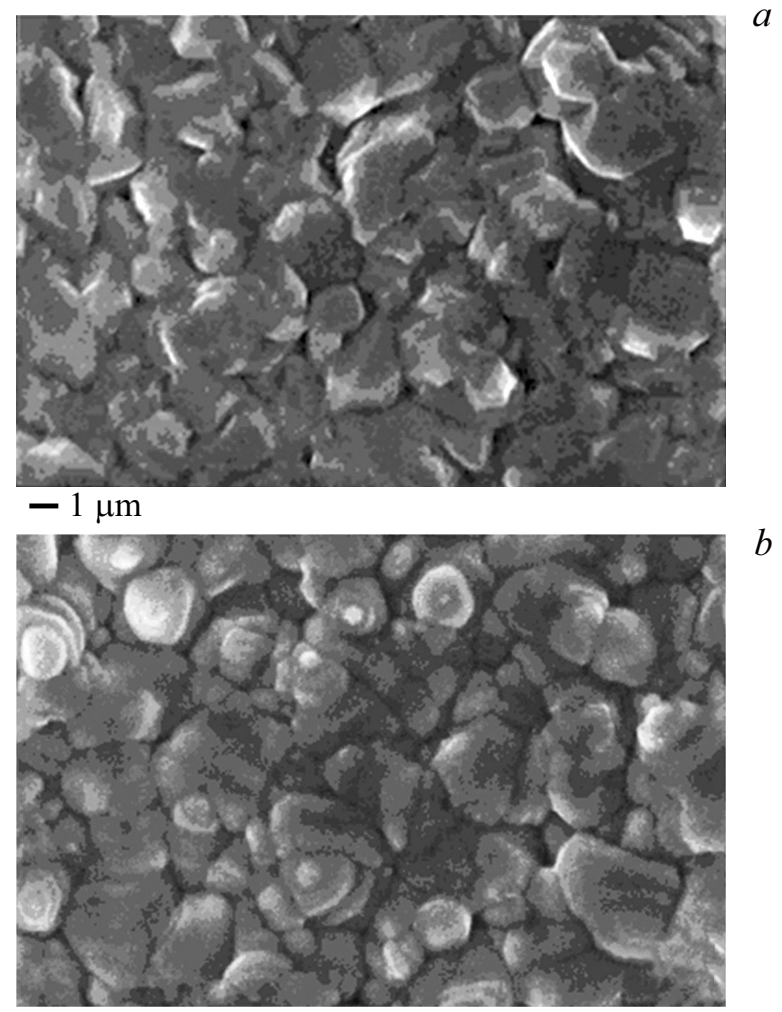

$-1 \mu \mathrm{m}$

Рис. 1. Микрофотография пленки теллурида кадмия, полученной путем сублимации в замкнутом объеме до $(a)$ и после отжига во фреоне на протяжении 30 мин $(b)$.

\section{3. Результаты и их обсуждение}

\section{1. Исследование влияния отжига во фреоне на кристаллическую структуру пленок теллурида кадмия, полученных сублимацией в замкнутом объеме}

Исследования морфологии поверхности слоев теллурида кадмия показали, что в исходном состоянии (рис. 1, $a$ ) зерна имеют размер 3-4 мкм. После отжига размер зерен незначительно увеличивается (рис. $1, b)$ и на поверхности зерен наблюдаются фигуры спирального роста.

При исследовании фазового состава, выполненном методом рентгеновской дифрактометрии, были выявлены отражения от плоскостей (111), (220), (311), 400), (331), (422), (511), (440), (531). Это однозначно свидетельствует о том, что в исходном состоянии пленки теллурида кадмия имели кубическую структуру цинковой обманки. Образцы имели незначительную преимущественную ориентацию в направлении [311]. При этом коэффициент преимущественной ориентации $G$ составлял всего 0.26 . Отжиг во фреоне приводит к изменению направления преимущественной ориентации: пленки теллурида кадмия становятся ориентированными в направлении [422]. При этом коэффициент преимущественной ориентации составляет 0.46. Смена ориентации с направления [331] на направление [422] свидетельствует о межзеренной перекристаллизации пленок, что подтверждается результатами исследования морфологии поверхности (рис. 1). Ориентация в направлении [422] свидетельствует о том, что отжиг приводит структуру ближе к термодинамическому равновесию. Это подтверждают и результаты прецизионного определения периода решетки слоев теллурида кадмия. Было установлено, что до отжига период кристаллической решетки составлял $6.491 \AA$, а после отжига $6.488 \AA$. Сравнивая эти значения с эталонным значением периода решетки теллурида кадмия $6.481 \AA$, можно заключить, что отожженные во фреоне пленки теллурида кадмия испытывают меньшие макродеформации.

Несмотря на то что пленка остается достаточно плотной после отжига во фреоне, границы между зернами проявляются более отчетливо и становятся более глубокими. При этом возникают локальные места, где толщина пленки становится заметно меньше среднего значения за счет ухода материала из более мелких зерен в крупные в процессе рекристаллизации.

\section{2. Влияние обработки во фреоне на выходные параметры и световые диодные характеристики солнечных элементов с базовым слоем теллурида кадмия, полученным сублимацией в замкнутом объеме}

Была изготовлена серия приборных структур glass $/ \mathrm{ITO} / \mathrm{SnO}_{2} / \mathrm{CdS} / \mathrm{CdTe} / \mathrm{Sb}_{2} \mathrm{Te}_{3} / \mathrm{Mo}$, в которых базовый слой теллурида кадмия, полученный методом осаждения в замкнутом объеме, подвергался отжигу во фреоне при температуре $400^{\circ} \mathrm{C}$ в течение разного времени. Световые BAX CЭ glass/ITO/SnO $2 / \mathrm{CdS} / \mathrm{CdTe} / \mathrm{Sb}_{2} \mathrm{Te}_{3} / \mathrm{Mo}$ представлены на рис. 2, а результаты их аналитической обработки приведены в табл. 1. Максимальное значение

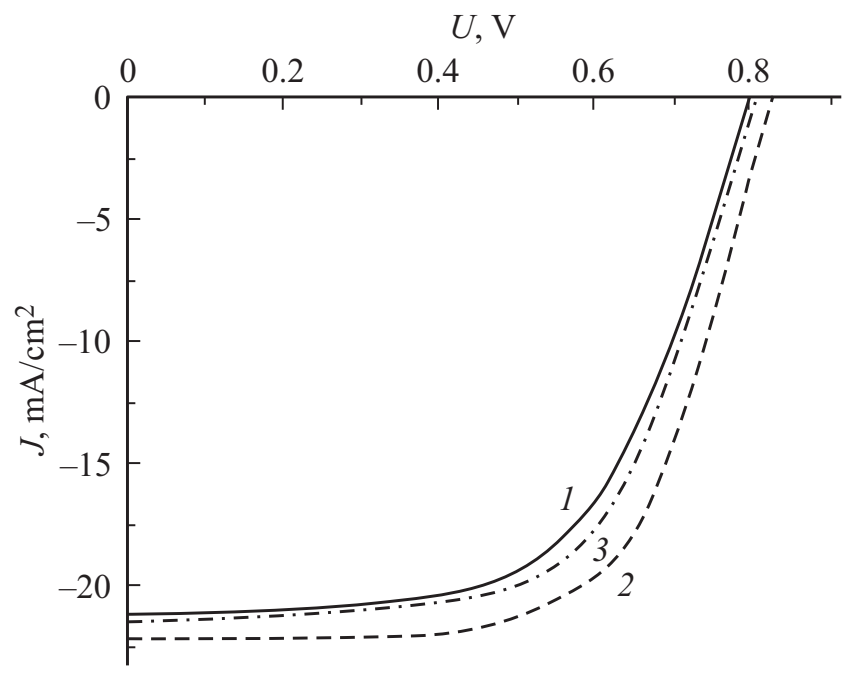

Рис. 2. Световые $\mathrm{BAX}$ CЭ glass $/ \mathrm{ITO} / \mathrm{SnO}_{2} / \mathrm{CdS} / \mathrm{CdTe} /$ $\mathrm{Sb}_{2} \mathrm{Te}_{3} / \mathrm{Mo:} 1-$ время отжига 20мин, 2 - время отжига 30 мин, 3 - время отжига 40 мин. 
Таблица 1. Влияние времени отжига во фреоне на выходные параметры и световые диодные характеристики СЭ glass $/ \mathrm{ITO} / \mathrm{SnO}_{2} / \mathrm{CdS} / \mathrm{CdTe} / \mathrm{Sb}_{2} \mathrm{Te}_{3} / \mathrm{Mo}$

\begin{tabular}{l|c|c|c|c}
\hline \multirow{2}{*}{$\begin{array}{c}\text { Выходные } \\
\text { параметры и } \\
\text { световые диодные } \\
\text { характеристики }\end{array}$} & \multicolumn{4}{|c}{ Время отжига во фреоне, мин } \\
\cline { 2 - 5 } & 20 & 30 & $30^{*}$ & 40 \\
\hline$J_{\mathrm{sc}}, \mathrm{мA} / \mathrm{cm}^{2}$ & 21.2 & 22.3 & 21.9 & 21.5 \\
$U_{\mathrm{oc}}, \mathrm{мB}$ & 794 & 821 & 820 & 800 \\
$F F$, отн. ед. & 0.59 & 0.64 & 0.68 & 0.62 \\
$\eta, \%$ & 10.0 & 11.7 & 12.2 & 10.7 \\
$J_{\text {ph }}, \mathrm{MA} / \mathrm{cm}^{2}$ & 21.3 & 22.4 & 22.0 & 21.8 \\
$R_{s}$, Ом $\cdot \mathrm{cm}^{2}$ & 5.4 & 4.5 & 3.6 & 6.4 \\
$R_{\mathrm{sh}}, \mathrm{Oм} \cdot \mathrm{cm}^{2}$ & 750 & 820 & 800 & 396 \\
$A$, отн. ед. & 2.6 & 2.2 & 1.88 & 1.62 \\
$J_{0}, \mathrm{~A} / \mathrm{cm}^{2}$ & $1.4 \cdot 10^{-7}$ & $1.0 \cdot 10^{-8}$ & $8.6 \cdot 10^{-10}$ & $9.6 \cdot 10^{-11}$
\end{tabular}

Примечание. * После облучения солнечным спектром АМ1 на протяжении 20 мин.

кпд $11.7 \%$ наблюдается при 30-минутном отжиге во фреоне (табл. 1). При этом одновременно улучшаются все выходные параметры. Дальнейшее увеличение времени отжига во фреоне приводит к снижению кпд, при этом все выходные параметры становятся хуже.

Как видно из результатов обработки ВАХ, при изменении времени отжига от 20 до 30 мин слабее всего изменяется фототок. Это связано с достаточно высоким исходным структурным совершенством слоев CdTe, полученных методом CSS. Небольшой рост плотности фототока связан с ростом времени жизни неравновесных носителей заряда после „хлоридной“ обработки, который обусловлен снижением скорости рекомбинации на зернограничной поверхности. Полагают, что в процессе „хлоридной“ обработки вблизи зернограничной поверхности происходит сегрегация дефектных комплексов акцепторного типа $\mathrm{Cl}_{\mathrm{Te}}-\mathrm{V}_{\mathrm{Cd}}$. Согласно [7], это приводит к формированию вблизи границ зерен $p^{+}$-областей, которые выталкивают неосновные носители в объем зерна.

Последовательное и шунтирующее сопротивления изменяются сильнее и примерно одинаково в пределах 10-20\%. Однако сильнее всего изменяется диодный ток насыщения, что позволяет сразу идентифицировать основной физический механизм, который отвечает за рост кпд. Этот механизм, с нашей точки зрения, связан с улучшением диодных свойств сепарирующего барьера за счет большего легирования базового слоя. Это подтверждается также и экспериментально зафиксированным увеличением напряжения холостого хода.

При изменении времени отжига от 30 до 40 мин все диодные характеристики, кроме фототока, изменяются существенно. Это не позволяет сразу идентифицировать физический механизм, который в конечном итоге отвечает за наблюдаемое изменение кпд. Поэтому полезно устанавливать количественную связь между кпд и световыми диодными характеристиками. Это позволит определить доминирующие световые диодные характеристи- ки, изменение которых при изменении технологических параметров изготовления СЭ обусловливает изменение его кпд. Для этого по методике, изложенной в [8] было выполнено моделирование влияния изменения световых диодных характеристик на кпд. При проведении моделирования влияния изменения световых диодных характеристик на кпд было установлено, что наблюдаемое экспериментально снижение кпд при увеличении времени отжига до 40 мин связано со снижением шунтирующего сопротивления и ростом последовательного сопротивления примерно в равной мере. Падение шунтирующего сопротивления приводит к снижению напряжения холостого хода, несмотря на дальнейшее уменьшение плотности диодного тока насыщения, которое свидетельствует о продолжающемся улучшении качества сеперирующего барьера. Авторы [9] полагают, что при термообработке во фреоне происходит диссоциация дихлорметана и последующая химическая реакция с образованием хлорида кадмия на поверхности теллурида кадмия:

$$
\mathrm{CdTe}_{\text {sol }}+2 \mathrm{Cl}_{2_{\text {gas }}} \rightarrow \mathrm{CdCl}_{2_{\text {gas }}}+\mathrm{TeCl} 2_{\text {gas }} .
$$

Затем протекают химические реакции, характерные для традиционной „хлоридной“ обработки [10]:

$$
\mathrm{CdCl}_{2_{\text {gas }}}+\mathrm{O}_{2_{\text {gas }}}+\mathrm{CdTe}_{\text {sol }}=\mathrm{TeCl}_{2_{\text {gas }}}+2 \mathrm{CdO}_{\text {sol }} \text {. }
$$

В использованной технологии изготовления CSS CЭ отсутствует операция травления, которая при традиционной хлоридной обработке позволяет удалить твердые продукты реакции, в частности $\mathrm{CdO}$, перед операцией изготовления тыльного контакта. При увеличении времени отжига до 40 мин образование окисла кадмия на поверхности базового слоя CdTe происходит в бо́льших количествах, чем это было при 30-минутном отжиге. Скорее всего, это и приводит к наблюдаемому росту последовательного сопротивления приборной структуры за счет увеличения сопротивления тыльного контакта.

Снижение шунтирующего сопротивления, на наш взгляд, связано со следующим. В процессе отжига в атмосфере фреона хлор попадает в объем зерен теллурида кадмия путем диффузии, при этом границы зерен будут легированы сильнее, так как являются путями ускоренной диффузии. Сегрегация хлора, теллура и кислорода обнаруживается не только на зернограничной поверхности теллурида кадмия, а и на межфазной границе $\mathrm{CdS} / \mathrm{CdTe}$ и даже на зернограничной поверхности сульфида кадмия [11]. При не слишком сильном легировании хлором границ зерен это легирование играет положительную роль, как было отмечено выше. Однако с увеличением времени отжига границы зерен легируются слишком сильно и на большую глубину в объем зерна, что приводит к снижению шунтирующего сопротивления. Кроме того, снижению шунтирующего сопротивления способствует и отмеченное выше уменьшение плотности пленки, и появление локальных утонений после отжига.

При исследовании деградационной стойкости СЭ glass $/ \mathrm{ITO} / \mathrm{SnO}_{2} / \mathrm{CdS} / \mathrm{CdTe} / \mathrm{Sb}_{2} \mathrm{Te}_{3} /$ Мо было установлено, 
что увеличение времени выдержки при освещении этих СЭ приводит к росту их эффективности на начальном этапе эксплуатации. Для образцов, в которых базовые слои отжигались в течение 30 мин, через 20 мин выдержки при освещении СЭ приводит к росту эффективности до $12.2 \%$ (см. табл. 1), после чего кпд стабилизируется на длительное время. В процессе выдержки на свету существенно изменяются диодный ток насыщения и последовательное сопротивление. Моделирование показало, что наблюдаемый экспериментально рост кпд обусловлен снижением последовательного сопротивления. Одним из возможных механизмов снижения последовательного сопротивления и плотности диодного тока насыщения при освещении образца может быть заполнение глубоких ловушечных уровней в базовом слое генерированными под действием света неравновесными носителями. Это приводит к росту времени жизни, $\tau$, неравновесных носителей заряда, в результате чего происходит уменьшение плотности диодного тока насыщения, который для разных моделей $p-n$-гетеропереходов обратно пропорционален корню из времени жизни $J_{0} \propto 1 / \tau^{1 / 2}$ [12]. Заполнение ловушек также может приводить к росту фотопроводимости пленок теллурида кадмия за счет увеличения подвижности носителей заряда.

\section{3. Влияние обработки во фреоне на кристаллическую структуру пленок теллурида кадмия, полученных термическим вакуумным испарением}

Исследование морфологии поверхности полученных методом термического испарения пленок теллурида кадмия показало, что размер зерен находится в диапазоне 0.5-1 мкм, структура слоя плотная (рис. 3,a).

После отжига во фреоне наблюдается изменение формы и размеров зерен (рис. $3, b)$. Границы зерен объединяются, и размер зерен увеличивается до 2-5 мкм. Однако в некоторых больших зернах, которые появляются в процессе рекристаллизации, наблюдаются внутренние границы, соответствующие исходным зернам. Это сви-

Таблица 2. Влияние отжига во фреоне на параметры кристаллической структуры слоев теллурида кадмия, полученных методом термического вакуумного осаждения

\begin{tabular}{|c|c|c|c|}
\hline $\begin{array}{c}\text { Структурные } \\
\text { характеристики }\end{array}$ & $\begin{array}{c}\text { После } \\
\text { осаждения }\end{array}$ & $\begin{array}{c}\text { Отжиг } \\
\text { во фреоне } \\
5 \text { мин }\end{array}$ & $\begin{array}{c}\text { Отжиг } \\
\text { во фреоне } \\
25 \text { мин }\end{array}$ \\
\hline $\begin{array}{l}\text { Направление } \\
\text { преимущественной } \\
\text { ориентации }\end{array}$ & {$[111]$} & {$[422]$} & {$[422]$} \\
\hline $\begin{array}{l}\text { Степень } \\
\text { преимущественной } \\
\text { ориентации } G\end{array}$ & 1.28 & 0.66 & 0.79 \\
\hline Период решетки $a, \AA$ & 6.509 & 6.488 & 6.487 \\
\hline
\end{tabular}
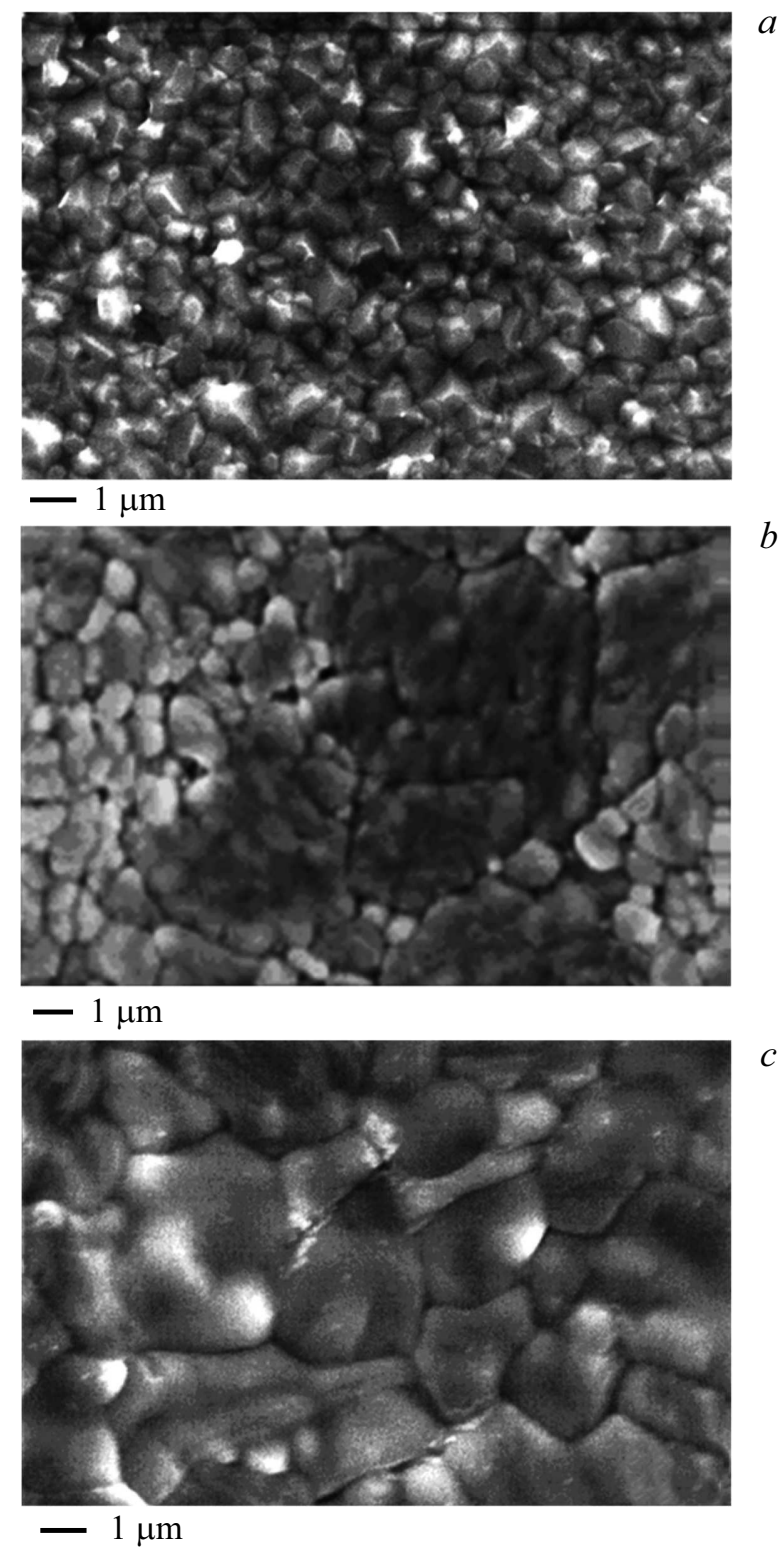

Рис. 3. Микрофотография поверхности слоя теллурида кадмия: $a-$ свежеизготовленные слои, $b-$ после отжига во фреоне в течение 25 мин при температуре $450^{\circ} \mathrm{C}, c-$ после проведения „хлоридной“ обработки в течение 25 мин при температуре $450^{\circ} \mathrm{C}$.

детельствует о незавершенности процесса. Плотность пленки уменьшается.

Рентгенодифракторметрическими методами было исследовано влияние времени отжига во фреоне на направление, степень преимущественной ориентации и период решетки базовых слоев (табл. 2).

Анализ табл. 2 показывает, что свежеизготовленные слои теллурида кадмия ориентированы в направлении [111], которое характеризуется максимальной скоростью роста. В таком направлении растут слои теллурида кадмия, осаждаемые в неравновесных условиях. Зерна теллурида кадмия, ориентированные в таком направ- 
Таблица 3. Выходные параметры и световые диодные характеристики СЭ с базовым слоем теллурида кадмия, полученным методом термического вакуумного испарения

\begin{tabular}{|c|c|c|c|c|c|}
\hline \multirow{2}{*}{$\begin{array}{c}\text { Выходные параметры } \\
\text { и световые диодные } \\
\text { характеристики }\end{array}$} & \multicolumn{5}{|c|}{ Температура $\left(T,{ }^{\circ} \mathrm{C}\right)$ и время $(t$, мин $)$ отжига } \\
\hline & $\begin{array}{c}T=500^{\circ} \mathrm{C} \\
t=25 \mathrm{Mин}\end{array}$ & $\begin{aligned} T & =450^{\circ} \mathrm{C}, \\
t & =25 \mathrm{Mин}\end{aligned}$ & $\begin{aligned} T & =450^{\circ} \mathrm{C}, \\
t & =20 \mathrm{Mин}\end{aligned}$ & $\begin{array}{c}T=400^{\circ} \mathrm{C} \\
t=25 \mathrm{Mин}\end{array}$ & $\begin{aligned} T & =450^{\circ} \mathrm{C}, \\
t & =25 \mathrm{Mин}\end{aligned}$ \\
\hline$J_{\mathrm{sc}}, \mathrm{MA} / \mathrm{cm}^{2}$ & 18.9 & 20.0 & 20.1 & 20.2 & 20.9 \\
\hline$U_{\mathrm{oc}}, \mathrm{MB}$ & 401 & 652 & 644 & 640 & 749 \\
\hline$F F$, отн. ед. & 0.32 & 0.55 & 0.53 & 0.53 & 0.64 \\
\hline$\eta, \%$ & 2.4 & 7.2 & 6.8 & 6.8 & 10 \\
\hline$J_{\mathrm{ph}}, \mathrm{MA} / \mathrm{cm}^{2}$ & 23.5 & 20.2 & 20.4 & 20.6 & 21.07 \\
\hline$R_{s}, \mathrm{OM} \cdot \mathrm{cm}^{2}$ & 2.8 & 3.1 & 5.0 & 4.7 & 3.7 \\
\hline$R_{\mathrm{sh}}, \mathrm{OM} \cdot \mathrm{cm}^{2}$ & 51 & 315 & 250 & 225 & 450 \\
\hline$A$, отн. ед. & 7.0 & 3.0 & 2.73 & 2.75 & 2.0 \\
\hline$J_{0}, \mathrm{~A} / \mathrm{cm}^{2}$ & $1.5 \cdot 10^{-3}$ & $4.1 \cdot 10^{-6}$ & $1.8 \cdot 10^{-6}$ & $2.1 \cdot 10^{-6}$ & $9.3 \cdot 10^{-9}$ \\
\hline
\end{tabular}

Примечание. * „Хлоридная“ обработка, с нанесением слоя хлорида кадмия.

лении, содержат высокую концентрацию двойников и дефектов упаковки, что существенно ограничивает эффективность фотоэлектрических процессов из-за роста скорости объемной рекомбинации неравновесных носителей заряда. Период решетки таких слоев составляет $6.509 \AA$ (см. табл. 2). Если учесть, что теоретическое значение периода решетки составляет $6.481 \AA$, то становится очевидным, что слои теллурида кадмия в исходном состоянии испытывают значительные макродеформации, обусловленные $10 \%$ различием периодов решетки слоев сульфида и теллурида кадмия. Необходимо отметить, что согласно литературным данным [11], слои сульфида кадмия оказывают ориентирующее влияние на рост пленок теллурида кадмия. В процессе отжига во фреоне в слоях теллурида кадмия наблюдается рекристаллизация. При этом пленки преимущественно ориентируются в направлении [422]. Это направление соответствует равновесным условиям роста. Период решетки слоев после отжига во фреоне приближается к теоретическому значению и составляет $6.487 \AA$.

Анализ поверхности слоев теллурида кадмия показал, что „хлоридная“ обработка с нанесением слоя $\mathrm{CdCl}_{2}$ (рис. 3,c) приводит к большему увеличению размеров зерен базовых слоев, чем при отжиге во фреоне (рис. $3, b)$, при этом пленка остается плотной без локальных утонений.

\section{4. Влияние обработки во фреоне на выходные параметры

Выходные параметры и световые диодные характеристики СЭ с базовым слоем теллурида кадмия, полученным методом термического вакуумного испарения, были определены путем аналитической обработки световых ВАХ. Исследовались СЭ, изготовленные при различных режимах отжига во фреоне. Результаты исследования представлены в табл. 3.

Было установлено, что для базовых слоев, подвергнутых отжигу во фреоне, максимальное значение кпд $7.2 \%$ наблюдается при температуре отжига $450^{\circ} \mathrm{C}$ и времени отжига 25 мин. При снижении времени отжига до 20 мин при этой температуре отжига наблюдается снижение кпд до $6.8 \%$ и напряжения холостого хода, при этом плотность тока короткого замыкания практически не изменяется (см. табл. 3). Анализ световых диодных характеристик показывает, что наблюдаемое экспериментально изменение выходных параметров в равной степени обусловлено снижением шунтирующего сопротивления и ростом последовательного сопротивления. Рост последовательного сопротивления, по-видимому, обусловлен тем, что при снижении времени отжига генерация электрически активных дефектов происходит не во всем объеме базового слоя. Для таких образцов наблюдается снижение шунтирующего сопротивления по сравнению со значением, характерным для оптимального времени отжига.

Снижение шунтирующего сопротивления при снижении времени отжига до 20 мин свидетельствует о неполной рекристаллизации базового слоя, в результате чего остается большое количество границ зерен, которые частично шунтируют сепарирующий барьер.

Для слоев теллурида кадмия, полученных термическим испарением снижение температуры отжига во фреоне от 450 до $400^{\circ} \mathrm{C}$ при фиксированном времени отжига (25 мин) приводит к таким же результатам, что и снижение времени отжига (см. табл. 3). Причины снижения выходных параметров также аналогичны.

Рост температуры от 450 до $500^{\circ} \mathrm{C}$ при фиксированной продолжительности времени (25 мин) приводит к снижению кпд до $2.4 \%$. При этом ВАХ принимает практически треугольный вид, в результате чего световые диодные характеристики нельзя определить достоверно. Однако низкое значение напряжения холостого хода 
и незначительное снижение величины тока короткого замыкания позволяют предполагать, что причиной снижения эффективности является шунтирование сепарирующего барьера. Возможный физический механизм снижения кпд аналогичен тому, который был рассмотрен при анализе снижения кпд фотоэлектрических преобразователей с базовыми слоями, полученными осаждением в замкнутом объеме при увеличении отжига во фреоне до 40 мин.

Сопоставление СЭ с базовым слоем, полученным методом термического вакуумного осаждения и подвергнутым традиционной „хлоридной“ обработке, и СЭ, которые были получены с применением отжига во фреоне (табл. 3), показывает, что последние значительно уступают практически по всем выходным параметрам. Моделирование показало, что определяющее влияние на рост кпд при проведении традиционной „хлоридной“ обработки оказывает снижение плотности диодного тока насыщения. На диаграмме состояний системы $\mathrm{CdC}_{2}-\mathrm{CdTe}$ при $77 \% \mathrm{CdCl}_{2}$ и температуре $508^{\circ} \mathrm{C}$ наблюдается эвтектика. При высокотемпературном отжиге наличие такой низкотемпературной эвтектики приводит к перекристаллизации теллурида кадмия. Процесс перекристаллизации поликристаллического базового слоя начинается путем образования зародышей в промежутках между зернами вблизи поверхности теллурида кадмия, контактирующей со слоем хлорида кадмия. Рост зародышей произвольной кристаллографической ориентации в условиях, близких к термодинамически равновесным, приводит не только к существенному увеличению размеров зерен, но и к оптимизации внутризеренной кристаллической структуры базовых слоев. Это приводит к увеличению времени жизни носителей заряда. При отжиге во фреоне не происходит эвтектической перекристаллизации базового слоя в условиях, близких к термодинамически равновесным, а размер зерен увеличивается в результате кристаллизационного отжига. Это видно на микрофотографии поверхности (см. рис. 3,b), где внутри некоторых больших зерен видны внутренние границы, которые принадлежали зернам исходной структуры. Кроме того, сравнивая микрофотографии (рис. $3, b$ и $c$ ), можно видеть, что рекристаллизация при отжиге во фреоне в отличие от традиционной „хлоридной“ обработки происходит неоднородно по площади пленки, и значительная часть зерен остается в исходных размерах, а пленка становится неплотной. Это приводит к более низким значениям шунтирующего сопротивления. Эвтектическая перекристаллизация базового слоя при традиционной „хлоридной“ обработке приводит к более сильному и равномерному легированию объема зерна. Увеличение степени легирования базового слоя и времени жизни неравновесных носителей заряда позволяет получить более высокий барьер и значительно меньшую величину плотности диодного тока насыщения, что и является основной причиной роста кпд при традиционной „хлоридной“ обработке.

\section{4. Заключение}

Рост эффективности СЭ с базовыми слоями теллурида кадмия, полученными сублимацией в замкнутом объеме и отожженными во фреоне при температуре $450^{\circ} \mathrm{C}$ до $11.7 \%$ при увеличении времени отжига во фреоне до 30 мин, обусловлен уменьшением плотности диодного тока насыщения. При дальнейшем увеличении времени отжига наблюдается снижение кпд за счет снижения шунтирующего сопротивления.

Освещение в режиме АM1 в течение 20 мин приводит к увеличению кпд СЭ на основе пленок теллурида кадмия, полученных сублимацией в замкнутом объеме, до $12.2 \%$, что связано с заполнением ловушечных уровней базового слоя генерированными под действием света неравновесными носителями заряда.

Было установлено, что при отжиге во фреоне слоев теллурида кадмия, полученных термическим вакуумным осаждением, наибольший рост эффективности, до 7.2\%, солнечных элементов на их основе наблюдается при температуре отжига $450^{\circ} \mathrm{C}$ в течение 25 мин. Рост температуры отжига свыше $450^{\circ} \mathrm{C}$ и времени отжига свыше 25 мин приводит к шунтированию сепарирующего барьера. При снижении времени отжига или снижении температуры отжига слоев теллурида кадмия снижение эффективности СЭ на их основе обусловлено снижением шунтирующего сопротивления и ростом последовательного сопротивления.

Проведенные исследования показывают, что метод отжига во фреоне в качестве альтернативы традиционной „хлоридной“ обработке может быть использован только в том случае, если исходные слои теллурида кадмия уже имеют достаточно высокое структурное совершенство. При этом для дальнейшего увеличения эффективности полученных таким способом СЭ следует предусмотреть операцию, которая позволит удалить продукты реакции, в частности $\mathrm{CdO}$, с поверхности $\mathrm{CdTe}$ перед формированием тыльного контакта, либо обеспечить минимально возможное количество примеси кислорода в процессе отжига во фреоне. Это позволит снизить последовательное сопротивление и повысить эффективность СЭ. Использование отжига во фреоне для слоев теллурида кадмия с низким исходным структурным совершенством не позволяет получить высокой эффективности СЭ. Это связано с тем, что рекристаллизация таких слоев в процессе отжига во фреоне происходит не полностью, в результате не удается достичь высокого качества сепарирующего барьера.

\section{Список литературы}

[1] K.J. Price. Proc. Materials Research Society Symposium (San Francisco, USA, 2001) p. H1.6.1.

[2] J.S. Lee, H.B. Im. J. Mater. Sci., 21, 980 (1986).

[3] N. Romeo, A. Bosio, R. Tedeschi. Proc. Int. Conf. 2nd Word Conf. on Photovoltaic Solar Energy Conversion (Vienna, Austrian, 1999) p. 235. 
[4] A. Romeo, M. Terheggen, D. Abou-Ras, D.L. Bätzner, F.J. Haug, M. Kälin. Progr. Photovolt.: Res. Appl., 12 (2-3), 93 (2004).

[5] H.R. Moutinho, F.S. Hasoon, F. Abulfotuh, K. Kazmerski. J. Vacuum Sci. Techn. A, 13 (6), 2877 (1995).

[6] H.S. Raushenbach. Solar Cells Array Design (N.Y., Litton Uducation Publishing, 1980).

[7] S.A. Galloway, A.W. Brinkman, R. Durose. Appl. Phys. Lett., 68 (26), 3725 (1996).

[8] G.S. Khrypunov, A.V. Meriuts. Ukr. J. Phys., 49 (12), 1188 (2004).

[9] N. Romeo, A. Bosio, A. Romeo. Solar Energy Mater. Solar Cells, 94, 2 (2010).

[10] M. Terheggen, H. Heinrich, G. Kostorz, D. Batzner, A. Romeo, A.N. Tiwari, N. Romeo, A. Bosio. Thin Sol. Films, 431-432, 262 (2003).

[11] M. Terheggen, H. Heinrich, G. Kostorz, A. Romeo, A.N. Tiwari. Proc. 17th Eur. Photovoltaic Solar Energy Conf. and Exhibition (Munich, Germany, 2002) p. 1188.

[12] B.L. Sharma, R.K. Purohit. Semiconductor Heterojunctions (Oxford, Pergamon Press, 1974).

Редактор Г.А. Оганесян

\title{
Influence of the freon annealing on crystalline structure of cadmium telluride layers and efficiency of thin film solar cells on their basis
}

\author{
G.S. Khrypunov, A.V. Meriuts, T.N. Shelest, \\ M.G. Khrypunov
}

National Technical University

„Kharkiv Polytechnic Institute“, 61002 Kharkov, Ukraine

Abstract In this paper the solar cells on thermal evaporation and close space sublimation on the basis of cadmium telluride base layers was investigated. Freon annealing was applied for activation of base layers. Structural and morphological researches were conducted for comparing of the recrystalization process in annealing in cadmium telluride base layers fabricated with different methods. The output parameters and light diode characteristics of solar cells are investigated and the possibility of using annealing in Freon vapors to create an industrial technology for the production of $\mathrm{CdS} / \mathrm{CdTe}$ film solar cells using thermal vacuum evaporation for the fabricate of base layers is analyzed. 